\title{
Tibial fibrous dysplasia in children treated by llizarov Technique- $A$ review of treatment options
}

\begin{abstract}
Fibrous dysplasia is a pathological condition, where normal medullary bone is replaced by fibrous tissue and small, woven specules of bone. Fibrous dysplasia can occur in epiphysis, metaphysis or diaphysis. Occationally, biopsy is necessary to establish the diagnosis. We present a review of operative treatment using the Ilizarov technique.
\end{abstract}

Keywords: fibrous dysplasia, tibia, deformity, children, Ilizarov apparatus
Volume 13 Issue 2 - 202 I

\author{
Bari MM,' Islam Shahidul, ${ }^{2}$ Ashraf Tanvir, ${ }^{3}$ Bari \\ AM Shayan $\mathrm{R}^{4}$ \\ 'Chief Consultant, Bari-llizarov Orthopaedic Centre,Visiting and \\ Honored Prof. Russian llizarov Scientific Centre, Russia \\ ${ }^{2}$ Professor, Bari-llizarov Orthopaedic Centre, Bangladesh \\ ${ }^{3}$ Consultant, NITOR, Bangladesh \\ ${ }^{4}$ Medical officer, Bari-llizarov Orthopaedic Centre, Bangladesh
}

Correspondence: Bari MM, Bari-llizarov Orthopaedic Centre, I/I, Suvastu Shirazi Square, Lalmatia, Dhaka-1207, Bangladesh, Tel +880181921 I595, Email bari.ilizarov3 I@gmail.com

Received: April 15, 2021 | Published: April 29, 2021

\section{Introduction}

The management of tibial fibrous dysplasia in children are curettage or subperiosteal resection to extra periosteal wide resection followed by bone transport. Here, enbloc excision followed by distraction osteogenesis is our main treatment technique. In few cases we did osteotomy in the true apex of the deformity and 2 smooth $1.5 \mathrm{k} /$ wires were introduced in the medullary cavity to maintain the axis and to prevent axis deviation. In this situation Ilizarov frame was applied with only the biocompatible thin wires. In the same sitting we can correct the deformity acutely. The potential advantage is to increase the bone regenerate. ${ }^{1,2}$ We describe 18 cases of fibrous dysplasia in tibia, in which 12 cases were treated by enbloc excision with bone transportation and 6 cases were treated by only application of Ilizarov with corrective osteotomy in the CORA, by putting the $1.5 \mathrm{~mm}$ two $\mathrm{k} /$ wires in the medullary cavity.

\section{Materials and methods}

A total of 18 patients were treated between January 2010 - January 2020; 12 patients came with pain and 6 with pain and deformity. All patients were treated by Ilizarov technique. Age ranges from 4-14 years. 12 patients by enbloc excision and bone transportation and 6 patients were treated by osteotomy at the true apex of the deformity by introducing the $\mathrm{k} /$ wires in the medullary cavity with stable fixation by Ilizarov device. The longest duration for bone transport was 16 weeks (14-20 weeks), and only for application, after deformity correction was 20 weeks. We have never used any kind of bone grafts.

\section{Results}

All the 18 patients were treated successfully by Ilizarov compression distraction device. The patients with localized tibial pathology with deformity had the shortest period on the Ilizarov apparatus, 14 weeks.

\section{Discussion}

There are varieties of treatment options in the literature, starting from casting, intramedullary nailing, plate and external fixator. Each with variable success rate and complications. The aim of this review was to showcase the outcomes with Ilizarov device. This is a unique tool with good outcomes and we are getting very less complications like wire track infection and that can be managed by local proper dressing and application of antibiotics. Fibrous dysplasia is caused by the sporadic mutation of the GNAS1 gene located on the chromosome of the osteoblastic cells. ${ }^{3}$ Fibrous dysplasia may occur in any bones. Fibrous dysplasia presents clinically in children and adolescents, with a median onset age of 5 years. Monostotic fibrous dysplasia is active and it became inactive after puberty. ${ }^{4}$ Children seek medical care because of either painful swelling and deformity or a pathological fracture through a weakened bone. Radiographically, monostotic fibrous dysplasia include a ground glass appearance with expansion of bone and sclerosis surrounding the lesion. ${ }^{5}$ MRI does not provide characteristic appearance of fibrous dysplasia. ${ }^{6}$ In our series we performed Ilizarov technique that in two ways:

a. We resected the whole tumor and then transported the bone after application of stable Ilizarov apparatus.

b. 2nd one, in the true apex of the deformity, we did osteotomy and put the $1.5 \mathrm{~mm}$ guide wires to increase circulation in the medullary cavity.

We have not done the intralesional curettage and bone grafting. Ilizarov technique has been well documented with good outcome in treating fibrous dysplasia by applying load and motion which gives good healing in pathologic area. ${ }^{5}$ Compression refers to the formation of new bone between the bony surface. It gives neovascularization, which is actually simulates the new bone formation. In addition, there is histogenesis of muscles, nerves, skin and disease like fibrous dysplasia. This new bone replaces pathological bone with normal bone. Due to its versatility, the Ilizarov apparatus allow 3-dimensional correction of deformity. The technique gives stability and creates mechanical force to induce the new bone formation which is compatible to Ilizarov's law of tension stress. ${ }^{7}$ The local blood supply and the integrity of the periosteum are well preserved by minimally invasive transosseous wires or when corticotomy is necessary. ${ }^{8}$ When vascularity is preserved at fracture site, the bone will unite within the normal healing period. ${ }^{9}$ And the greatest advantage after application of the Ilizarov apparatus is early weight bearing. Weight bearing is considered to be essential both for bone regeneration and consolidation. 

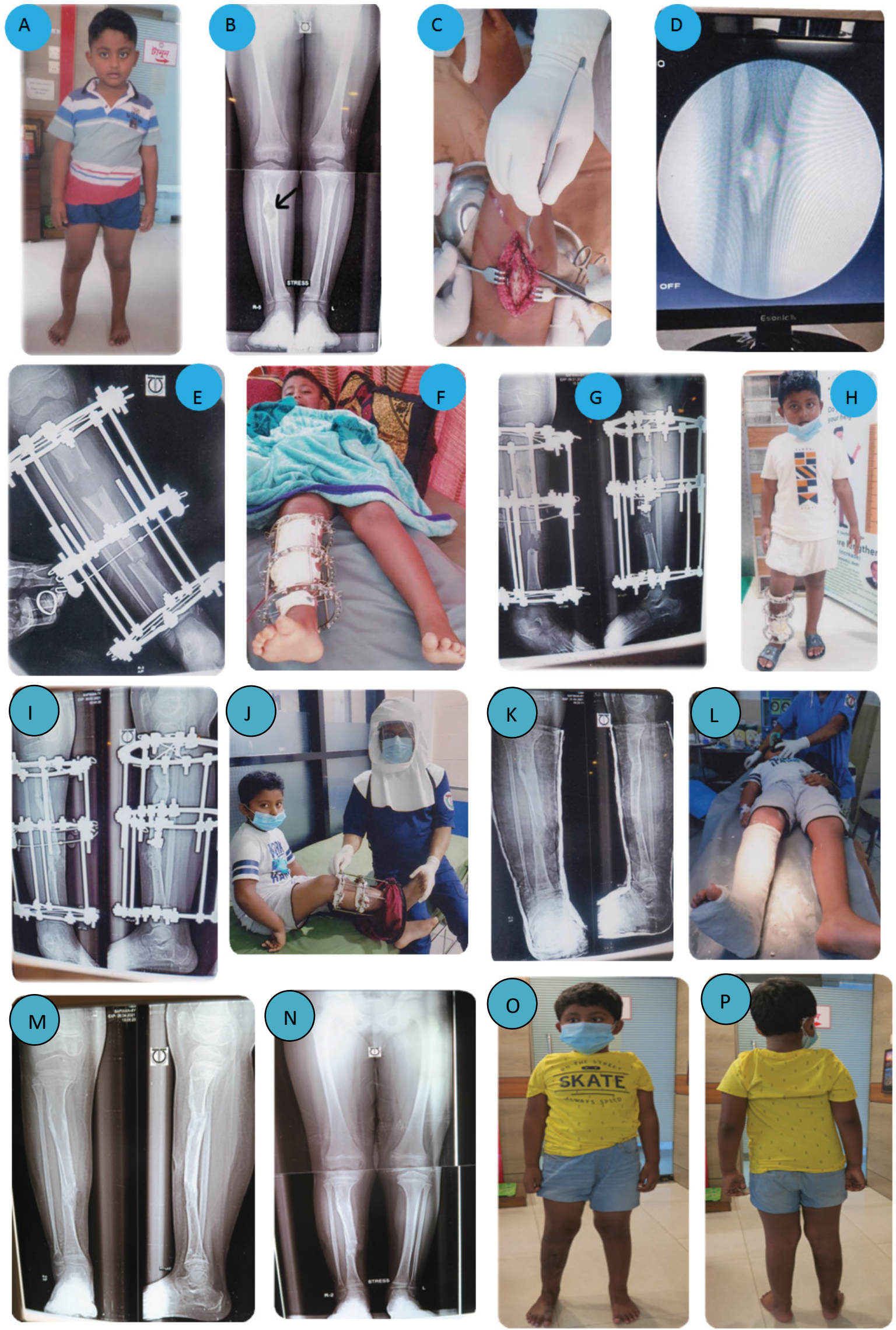

Figure 16 years old boy. 


\section{Histopathology report:}

\section{Gross:}

Bony fragments, total quantity about $5 \mathrm{ml}$. (All taken).

\section{Micro:}

Tissue fragments showing feature suggestive of fibrous dysplasia. Please correlate with clinical and radiological Findings.

(A) Clinical appearance of the patient Fibrous dysplasia.

(B) Radiographic view, right sided Fibrous dysplasia before surgery.

(C) Curattege and Enbloc excision.

(D) Fluroscopic view after curattege.

(E) Enbloc excision with Ilizarov application and corticotomy in the lower tibia.

(F) Patient with Ilizarov apparatus.

(G) Radiographic view of bone transport.

(H) Standing position of the patient with Ilizarov apparatus.

(I) Radiographic view after 3 months and 15 days with bone transportation and consolidation.

(j) Prof. M. M. Bari with the patient. (K, L) After removal of llizarov apparatus, plaster immobilization.

$(\mathrm{M}, \mathrm{N})$ Final radiographic view after 4 months and 12 days with bone transportation and consolidation.

$(\mathrm{M}, \mathrm{N})$ Clinical appearance of the patient (Front \& back view) after 4 months and 12 days with bone transportation and consolidation.

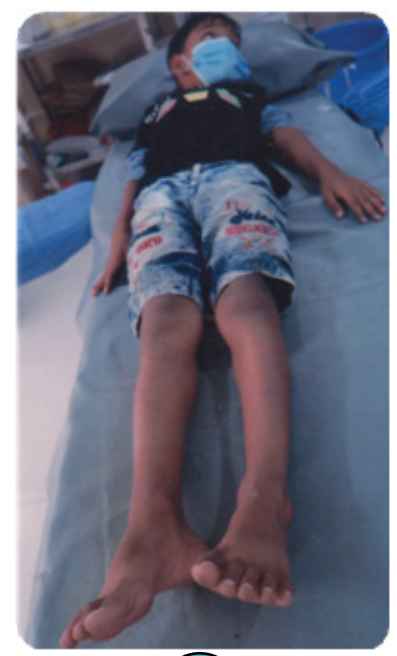

A

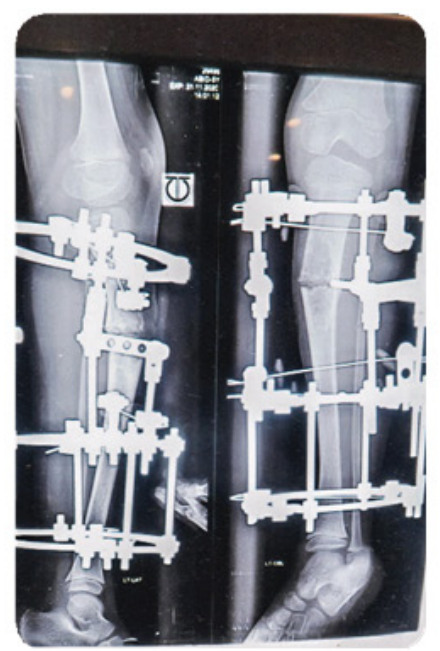

E
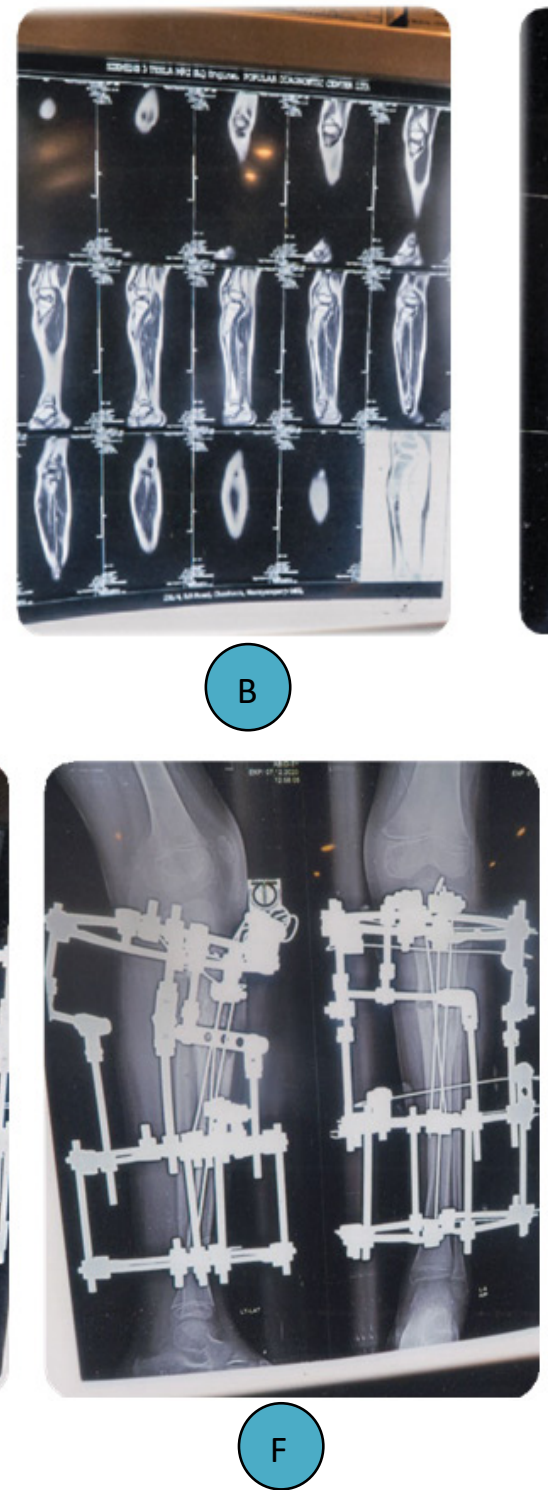

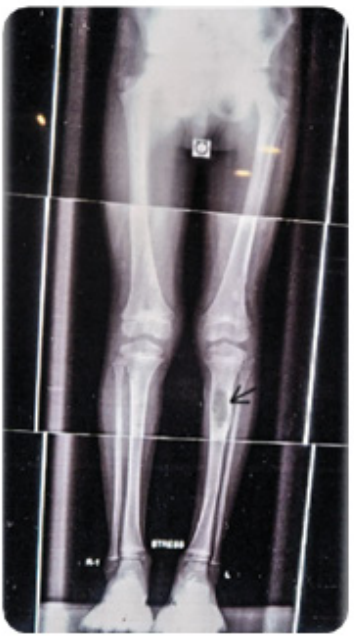

(C)
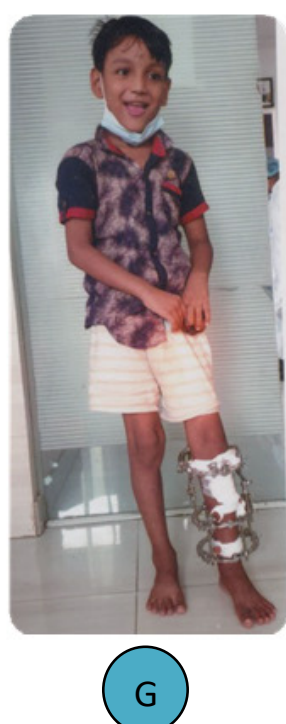

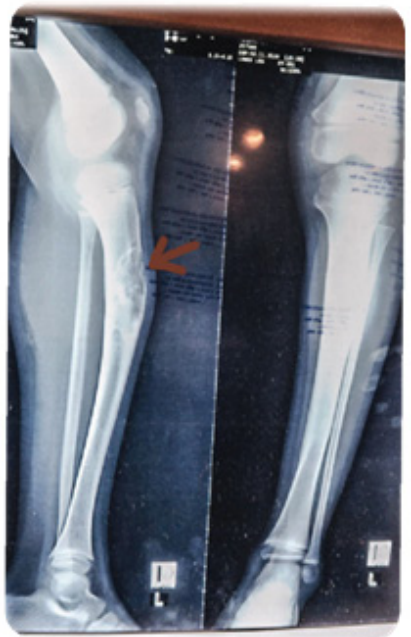

(D)

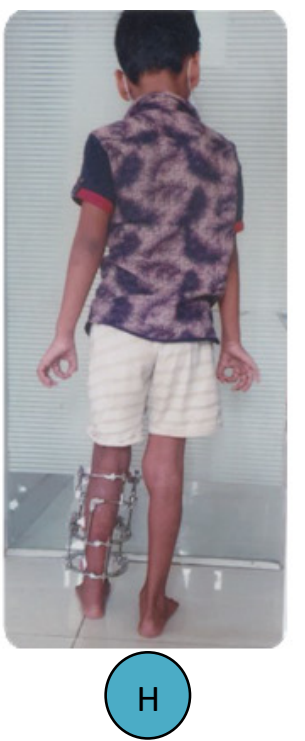

Citation: Bari MM, Shahidul I, Tanvir A, et al.Tibial fibrous dysplasia in children treated by llizarov Technique- A review of treatment options. MOJ Orthop Rheumatol. 202 I;I3(2):26-29. DOI: I0.I5406/mojor.202I.I3.00542 

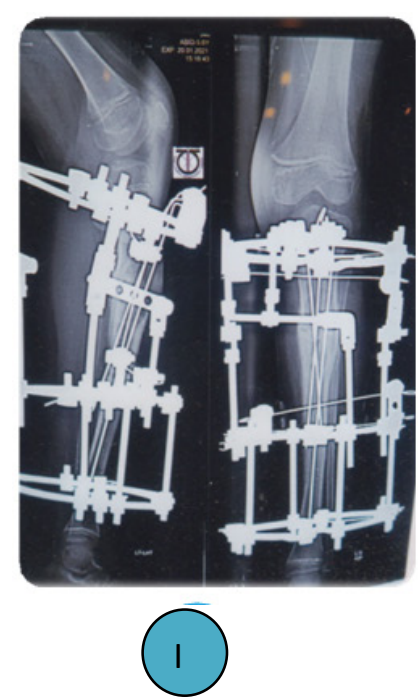
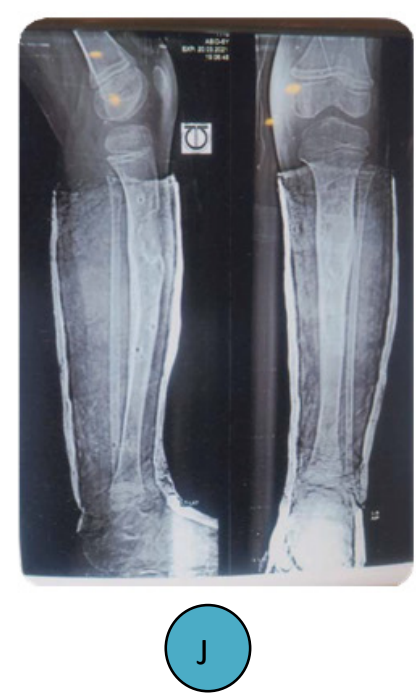
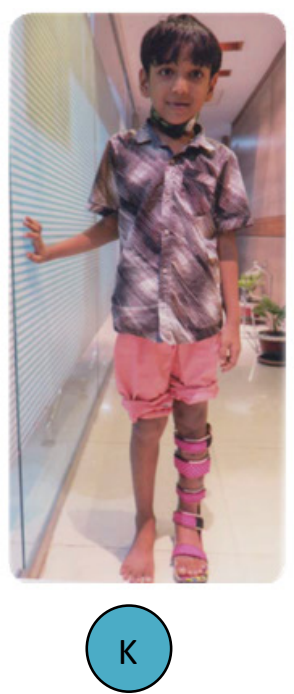

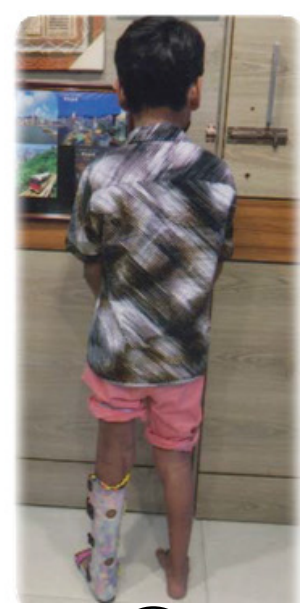

L

Figure 25 years old boy.

Histopathology report:

Gross description:

Multiple pleces of soft and bony tissue fragments, soft tissue collectively measure $(10 * 08 * 06)$.

$\mathrm{mm}^{3}$ and bony tissue collectively measure $(8 * 5 * 2) \mathrm{mm}^{3}$.

Sections code: A) All soft tissue embedded on one block, B) All soft tissue embedded on one block.

Microscopic description:

Sections from the submitted specimen reveal a lesion composed of Chinese figure-like trabeculae of woven bone within a proliferating Fibroblastic stroma. Osteoblastic rimming of these trabeculae is seen. No granuloma or evidence of malignancy is seen.

\section{Histologic diagnosis:}

Tissue from tibia, left: Consistent with

\section{Fibrous dysplasia}

(A) Clinical appearance of the patient Fibrous dysplasia.

(B) CT scan of left tibia.

(C, D) Radiographic view, left sided Fibrous dysplasia with procurvatum before surgery.

(E) Correction of the procurvatum deformity with simple osteotomy.

(F) Two 1.5 smooth $\mathrm{k} /$ wires throug the medullary cavity introduced.

$(G, H)$ Smiling patient with llizarov apparatus (Front and back view).

(I) Before dismounting the llizarov apparatus after 3 months since the application of Ilizarov apparatus.

(j) After removal of llizarov apparatus, plaster immobilization.

(K, L) Patient is on AFO (Ankle Foot Orthosis).

\section{Acknowledgments}

None.

\section{Conflicts of interest}

The authors declare no conflicts of interest.

\section{References}

1. Ernesto Ippolito, Edward W Bray, Alessandro Corsi, Fernando De Maio, Ulrich G Exner, et al. Natural history and treatment of brous dysplasia of the bone: a multicenter clinicopathologic study promoted by the European Pediatric Orthopaedic Society. J Pediatr Orthop B. 2003;12(3):155-157.

2. Sakurakichi K, Tsuchiya H, Yamashiro T, et al. Ilizarov technique for the correction of the Sheperd's crook deformity: a report of two cases. $J$ Orthop Surg (Hong Kong). 2008;16(2):254-256.

3. Di Caprio MR, Enneking WF. Fibrous dysplasia. Pathophysiology, evalustion, and treat-ment. J Bone Joint Surg Am. 2005;87(8):1848-1864.
4. Lichtenstein L, Ja e HL. Fibrous dysplasia of bone. A condition a ecting one, several or many bones, the graver cases of which may present abnormal pigmentation of skin, premature sexual development, hyperthyroidism or still other extra skeletal abnormalities. Arch Pathol. 1942;33:777-816.

5. Singer FR. Fibrous dysplasia of bone: The bone lesion unmasked. Am J Pathol. 1977;151(6):1151-1155.

6. Chan B, Zacharin M. Pamidronate treatment of polyostotic brous dysplasia: Failure to prevent expansion of dyspllastic lesions during childhood. J Pediatr Endocrinol Matab. 2006;19(1):75-80.

7. Bari MM. A color atlas of limb lengthening, surgical reconstruction and deformity correc-tion by Ilizarov technique. 2013;382,383.

8. Bari MM. Correction of leg deformities and restoration of function of leg bones by Iliza-rov technique. 2016;125.

9. Tsuchiya H, Tomita K, Matsumoto T, et al. Shepherd's crook deformity in brous dysplasia. Clin Orthop Relat Res. 1995;310:160-164. 